http://dx.doi.org/10.12795/PH.1989.v04.i02.33

\title{
TÉCNICAS NARRATIVAS EN LAS NOVELAS DE HEINRICH BÖLL
}

\author{
$M^{a}$ Clara Ubieto Artur \\ Titular Interina de Escuela Universitaria \\ Dep. de Filologías Integradas \\ Sección de Filología Alemana
}

Aunque no se puede decir que Böll descuide la construcción de sus obras épicas más pretenciosas - sus novelas-, la estructura que presentan las primeras suele estar más bien poco elaborada. Hay que constatar, sin embargo, una evolución bastante evidente en su técnica, que apreciamos al analizar la estructura narrativa de sus novelas ${ }^{1}$.

La primera que publica, Wo warst du, Adam?, es de tema bélico, muy lejos, en cuanto al tratamiento de la guerra misma y de los personajes de las novelas de Remarque o Jünger.

En ella, el eje de la narración discurre linealmente, aunque con interrupciones, directamente hacia el final. Lo que sustenta la novela son los personajes, de los cuales hay uno que parece el hilo conductor. Así, en el primer capítulo, se presenta al soldado Feinhals, que tiene la función de servir de vínculo entre los distintos personajes de la novela. En el mismo capítulo se nos habla de otros dos soldados heridos sin mencionar su nombre. Pero en el capítulo dos, Feinhals reconocerá a uno de los heridos, del mismo modo que en el capítulo tres retomará el narrador la historia del segundo de los heridos.

El capítulo cuarto está dedicado a un nuevo soldado, Greck, que desaparece del hilo de la narración para reaparecer en el capítulo 6, donde se describe su muerte. Vuelve a centrarse la narración en Feinhals en el capítulo 5, en que se describe su relación amistosa con una judía, Ilona. Esta joven desaparece durante el capí-

1 Hay que dejar de lado sus narraciones, ya que, a pesar de que son a veces tan extensas como alguna de sus novelas, se consideran narraciones precisamente por la escasa complejidad de su estructura narrativa. Así sucede con narraciones como Der Zug war pünktlich, que es tan amplia como la novela Wo warst du, Adam? pero presenta una estructura muy simple. 
tulo 6, para reaparecer en el siete, en el que es asesinada. Y de nuevo es Feinhals el que servirá de hilo conductor durante los capítulos 8 y 9 .

\begin{tabular}{|c|c|c|c|c|}
\hline Capítulo: & $\begin{array}{l}1 \\
\text { Feinhals } \\
\text { herido A } \\
\text { herido B }\end{array}$ & $\begin{array}{l}2 \\
\text { Feinhals } \\
\text {.Bressen }\end{array}$ & $\begin{array}{l}3 \\
\text { Feinhals } \\
\text {.Bauer }\end{array}$ & \\
\hline Capítulo: & $\begin{array}{l}4 \\
\text { Greck.... }\end{array}$ & $\begin{array}{l}5 \\
\text { Feinhals }\end{array}$ & $\begin{array}{l}6 \\
\text { Feinhals } \\
\text { Greck }(+)\end{array}$ & 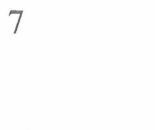 \\
\hline & & Ilona.... & (n............ & Ilona $(+)$ \\
\hline Capítulo: & $\begin{array}{l}8 \\
\text { Feinhals }\end{array}$ & $\begin{array}{l}9 \\
\text { Feinhals }\end{array}$ & & \\
\hline
\end{tabular}

Hay además una serie de soldados y campesinos que rodean al ejército y viven de él. Pero el papel de éstos será secundario en el desarrollo de la novela. Böll no recurre al uso de anacronías de ningún tipo. La historia discurre desde el día en que Feinhals llega a un batallón y es herido, hasta un punto final y casi previsible: el día en que el soldado muere.

La novela, de duración lineal, tradicional y clásica en su arquitectura, está compuesta en realidad por varias narraciones breves, vinculadas entre si por un protagonista (Feinhals). En esta, lo importante es describir la guerra como una enfermedad ${ }^{2}$ en la que toman parte enfermos que se enfrentan a un enemigo que, salvo en contadas ocasiones, nunca se materializa. En esta guerra no hay ni un solo acto heroico, únicamente el gran absurdo que es la guerra, una sucesión de acciones que no llevan a ningún lado, un despilfarro de vidas, energías y de material.

Una estructura semejante presenta la novela publicada en 1953 Und sagte kein einziges Wort. Cada capítulo le corresponde a uno de los dos personajes; un matrimonio que vive separado en la posguerra alemana. Los capítulos 1, 3, 5, 7, 9 y 13 tienen a Fred Bogner como protagonista. Los capítulos 2, 4, 6 y 8 a su mujer Käte. Los capítulos 10, 11 y 12 a ambos. Las acciones que se describen, los monólogos interiores de los dos protagonistas son simultáneos, sin embargo, parecen más dadas por exigencias de la propia narración que por voluntad expresa del autor ${ }^{3}$.

Ambas novelas no abarcan más de lo que narran en el desarrollo de la acción propiamente dicho. De por si son bastante significativas, pero aun resultan poco

2 Ya nos lo indica la cita que Böll recoge de Saint-Exupéry y con la que abre la novela: «Früher habe ich Abenteuer erlebt: die Einrichtung von Postlinien, die ueberwindung der Sahara, Südamerika - aber der Krieg ist kein richtiges Abenteuer, er ist nur Abenteuer-Ersatz. Der Krieg ist eine Krankheit. Wie der Typhus».

3 Y esto se aprecia mejor si comparamos, la estructura de esta novela con la de Billard um halb$z e h n$, en la que resulta evidente su utilización. 
profundas si se las compara con las novelas siguientes. La propia estructura acota el campo de acción del autor: se limita la primera a la experiencia de varios años - sin determinar - en el frente de un joven soldado alemán y, la segunda, a los tres días de la vida de un matrimonio.

Mayor complejidad se observa en la novela Haus ohne Hüter, publicada en 1954. Es bastante más amplia que las anteriores aunque su estructura refleja similitudes: cada capítulo (hay 22 en total) le corresponde (aunque no exclusivamente) a uno de los personajes, siendo los principales cinco: Martín y Heinrich, dos huérfanos de padre y sus respectivas madres, Nella y Wilma, así como el amigo de Nella y sustituto de la figura paterna de los dos niños: el tío Albert. La complejidad y profundidad de la novela vienen dadas por los propios personajes: en el capítulo 1 el narrador nos cuenta la historia de Martín y la de su madre. En el capítulo 2 nos describe la de Heinrich. Utiliza el punto de vista de los dos niños. Los capítulos 3 y 4 les corresponden a Nella y Wilma, las dos viudas. Los capítulos 5 y 6 de nuevo a Martín y Heinrich. Parece que la alternancia va a ser regular y simétrica, pero el narrador se interesa más por la historia de Nella, viuda de un poeta de reconocida fama que por Wilma, cuyo marido era cerrajero y no se presta tanto a lo que resulta característico de Heinrich Böll: la crítica mordaz del presente en fuerte contraposición con el pasado.

No es que el presente se encarne en Nella, la mujer que ha visto truncadas todas sus esperanzas de una vida que ella se imaginaba feliz junto al único hombre que ha amado. Ni que el pasado se encarne en la figura de Gäseler, el responsable directo de la muerte del joven poeta. Lo que se opone en realidad es el presente y pasado del mismo personaje, en este caso Gäseler. Y ahí reside lo perverso de la situación: Gäseler trabaja como redactor de una revista católica. Gäseler; la misma persona que sacrifica al marido de Nella durante la II Guerra Mundial para hacer valer ante todo su autoridad de oficial:

«Es war in Sommer 42. (...) Es war ein neuer Leutnant gekommen, der rundschlich, um die Leute seines Zuges zu sehen. Es war Gäseler. Bei uns blieb er länger als bei den andern liegen -es war alles ruhig, und er sagte: 'Ich suche zwei intelligente Leute'.

Wir schwiegen.

'Zwei intelligente Leute suche ich'.

'Wir sind nicht intelligent', sagte Rai.

'Das einzige, was ihr überhaupt seid, ist intelligent'.

'Haben wir Brüderschaft miteinander getrunken?' sagte Rai. (...) Diese Antwort entschied über Rais Schicksal. (...)

«Gäseler bestimmte uns zu einem Spähtrupp, den auszuführen wir völlig ungeeignet waren. Alle Leute waren vernünftig, der Feldwebel, der uns kannte, riet Gäseler ab (...). Alle Leute redeten es Gäseler aus -aber er schrie nur: 'Es fragt sich, ob der Befehl eines Offizziers ausgeführt werden mu $\beta$ oder nicht» ${ }^{4}$.

El resultado es la muerte de Rai.

4 H. Böll; Werke. Romane und Erzählungen. Haus ohne Hüter. Kiepenheuer \& Witsch, Köln. págs. $422-423$. 
Gäseler, el verdugo, no recuerda ni quiere recordar nada de la guerra ${ }^{5}$, mientras que la viuda, el hijo y amigo del muerto (las víctimas) no pueden dejar de pensar en ello. Aunque acaben descubriendo que también el odio, que durante tantos años han ido alimentando, se ha agotado.

Es la novela Billard um halbzehn, publicada en 1959, la que la crítica ha venido considerando como la obra en que Böll alcanza la maestría como novelista. En ésta se utiliza la técnica del contrapunto como recurso evidente. Casi toda la novela, que se desarrolla en el plazo de un día, consta de acciones simultáneas narradas a veces desde solo un punto de vista, a veces desde perspectivas diferentes. Esta técnica resulta palpable en el último capítulo, el 13, en el que se narra una misma acción desde tres perspectiva distintas. En los capítulos anteriores se narran los acontecimientos de modo que algunas acciones se superponen en el tiempo, son simultáneas. Le corresponde a cada personaje un capítulo.

En el capítulo 1, que se extiende de las 11.30 a las 12, el arquitecto Robert Fähmel llama a su secretaria por teléfono. Después, el padre de éste visitará a la empleada para proponerle un trabajo. La acción del capítulo 1 se desarrolla íntegra en las oficinas del arquitecto. El capítulo 2 nos retrotrae en el tiempo, ya que se desarrolla desde algún momento después de las 9.30 (hora en que llega Robert Fähmel a un hotel para jugar su partida de billar) hasta poco antes de las 11, en que ésta queda interrumpida a causa de una visita inesperada. El capítulo 3 describe la partida de billar, es decir, se extiende de las 9.30 hasta poco antes de las 11 (ya nos ha descrito el narrador al intruso que interrumpirá la partida antes de la hora habitual).

El capítulo 4 retoma el personaje del abuelo: esta vez en su propia oficina, organizando el material con Leonore, la secretaria. La jornada de trabajo termina a las 14.00, cuando llega el taxi que le llevará al sanatorio donde está recluida su mujer.

El capítulo 5 se desarrolla íntegro en el sanatorio donde la Sra. Fähmel recibe las visitas de su hijo Robert y de su marido por separado. Queda concertada una cita en el bar de la estación entre padre e hijo (que se cruzan en la entrada del sanatorio). Esta cita ocupa todo el capítulo 6, y está perfectamente cronometrada: de las 15.40 a las 16.10 , momento en que llega el tren en que se reunen con Ruth, la hija de Robert. Los tres acuden a visitar la abadía que el viejo Fähmel contruyera en su juventud.

El capítulo 7 se desarrolla a partir de las 15.30. La acción empieza en la cárcel (Schrella, el mejor amigo de Robert Fähmel y compañero en el exilio es recogido de la prisión por Nettlinger, el responsable de su paso por la misma) y se traslada al hotel (Nettlinger invita a Schrella a comer). Apenas empieza la refección, Schrella abandona el lugar.

5 Sin embargo, la guerra es en realidad algo todavía familiar para él:

«Wo waren Sie im Krieg?»

(...) «Fast überall», sagte er. «Im Westen, im Osten, im Süden nur im Norden nicht. Zuletzt bin ich in Erwins Armee».

Se refiere a Rommel. Es la perversión del sentimentalismo plasmada en el responsable de una muerte que él no recuerda y su viuda no puede olvidar. Sin embargo se refiere a los grandes militares por su nombre de pila. 
El narrador se concentra a lo largo del capítulo 8 en Marianne y Joseph, el hijo de Robert Fähmel. Su conversación empieza a las 16.20 y ha de ser interrumpida para llegar a tiempo a la visita de la abadía (vid. capítulo 6) en la que han quedado citados con el resto de la familia. No quieren llegar más tarde de las 17.00 horas. Esta visita será descrita a lo largo del capítulo 10.

El capítulo 9 retoma el personaje de Schrella en sus paseos por la ciudad hasta que encuentra una pensión.

De nuevo se centra el narrador, en el capítulo 11, en el personaje de la abuela recluida en el sanatorio. Y esta vez no huirá del tiempo, sino que decide volver a la realidad y enfrentarse a ella. Son las 18 horas y a las 19 es la fiesta de cumpleaños de su marido.

El capítulo 12 se desarrolla de nuevo en el hotel. Es algo más tarde de las 18; las habitaciones desde las que han decidido ver fuegos artificiales y un desfile están reservadas para las 18.30. Sin embargo, la fiesta queda trastocada por los acontecimientos que se narran en el último capítulo, en que la simultaneidad de los hechos es aún más patente.

En este capítulo, la anciana Sra. Fähmel dispara desde la ventana en que contempla el desfile contra un político. Este disparo se describe desde tres perspectivas distintas. Lo escuchan los tres jóvenes (Ruth, Joseph y Marianne) antes de entrar en el hotel:

«Mein Gott», sagte Marianne ängstlich, «was war das?» «Das war ein Schuß», sagte Joseph ${ }^{6}$.

Lo escucha Leonore, justo después de hablar por teléfono desde recepción con su jefe:

«Sie legte den Hörer auf, ging auf den Portier zu, öffnete schon den Mund, um nach dem Weg zu Fähmels zu fragen, als ein fremdes, nicht sehr lautes, sprödes Geräusch sie erschreckte».

«Mein Gott», sagte sie, «was war das?»

«Das war ein Pistolenschu $\beta$ mein Kind», sagte Jochen ${ }^{7}$.»

Y sorprende a Robert y su amigo Fähmel, que están conversando en la sala de billar. Aún se repite la conversación telefónica que mantiene con su secretaria y de nuevo el disparo:

«Robert lagte den Hörer auf und wandte sich wieder Schrella zu:

«Ich glaube», sagte er-aber ein fremdes, nicht sehr lautes, sprödes Geräusch unterbrach ihn.

«Mein Gott», sagte Schrella, «das war ein Schuß».

«Ja», sagte Robert, «das war ein Schuß. Ich glaube, wir müssen jetzt nach oben gehen» ${ }^{8}$.

6 Böll, H.: Werke. Romane und Erzählungen. Billard um halbzehn. Kiepenheuer \& Witsch, Köln pág. 520.

7 Ibíd. pág. 522.

8 Ibíd. pág. 530 . 
La estructura de esta novela está visiblemente mas elaborada que la de las anteriores. También la simultaneidad tan marcada de las acciones es nueva ${ }^{9}$. Böll no volverá a recurrir a esta técnica en obras posteriores. Billard um halbzehn es, en cierto modo, una excepción en este aspecto.

Volvemos a encontrar aquella oposición presente/pasado que ya quedó señalada en Haus ohne Hüter (vid. supra). En esta se trataba de Gäseler, responsable de la muerte de un poeta al que no dudará en citar en la conferencia que mantendrá ante su propia viuda. En aquella se trata de un antiguo profesor de gimnasia, nazi fanático, que ocupa un puesto de responsabilidad en la República Federal de finales de los cincuenta y del que se puede decir que es de «los que no aprenden»:

(...) «er ist erst achtundfünfzig, und du wirst das Wort aus meinem Munde bestimmt komisch finden: er ist einer von den Unbelehrbaren» ${ }^{10}$.

Después de Billard um halbzehn se publica Ansichten eines Clowns en el año 1963. En ésta no recurre Böll a la técnica de que se sirviera en su obra anterior, ya que solo existe un protagonista/narrador. El relato primero se reduce a tres horas y media, en que el protagonista, Hans Schnier (un payaso fracasado, tanto profesional como sentimentalmente) se dedica a recordar el pasado y a llamar por teléfono a amigos y parientes para pedirles ayuda. Lo que le posibilita al narrador el análisis de la sociedad alemana, tanto su pasado como su presente, son precisamente las anacronías, que amplían el tiempo que abarca ese reducido relato primero.

El teléfono desempeña un papel muy importante en esta novela, ya que es el único contacto que tiene Schnier con el mundo exterior y, al mismo tiempo es el recurso estilístico que justifica las analepsis: antes de efectuar la llamada, Schnier recuerda algunas características de la persona con la que va a establecer contacto.

9 Nuevo en Heinrich Böll, no así en el panorama literario europeo, ya que «die Methode stammt von den jüngeren französische Romanciers: Robbe-Grillet, Michel Butor, Claude Simon, Claude Mauriac und anderen». (K. A. Horst, «Ueberwindung der Zeit». Der Schriftsteller Heinrich Böll. Hrs. v. W. Lengning. DTV, 1977, pág. 77. Böll no ha pasado a la historia de la literatura por las innovaciones en la lengua, ni por un estilo original del que carece. Ya se ha indicado en numerosas ocasiones la adaptación estilística que lleva a cabo Böll basándose en modelos como Hemingway (el mismo Böll hace referencia a este guía en la entrevista "Werkstattgespräch mit Bienek», celebrada en 1961 y publicada en la editorial Kiepenheuer \& Witsch: Werke. Intewiews. Bd. I), Faulkner o Salinger (Cfr. Schröter, Kl.: Böll. Rowohlt Verlag, Reinbeck bei Hamburg, 1982). Se han apuntado también ciertas similitudes estilísticas con Borchert (H. M. Waidson, «Die Romane und Erzählungen Heinrichs Bölls») o con G. Greene (H. Plard, «Mut und Bescheidenheit»). En: Der Schriftsteller Heinrich Böll. Editado por W. Lengning, DTV, München, 1977. El interés del autor Heinrich Böll reside en el contenido de sus novelas primordialmente:

«(...) Handlung als solche, also im Sinne der epischen Technick ... interessiert mich gar nicht so sehr ... Mich interessieren Personen, Situationen, mehr innere Vorgänge». (En: Durzak, M.: Der deutsche Roman der Gegenwart. Kohlhammer, Stuttgart, 1971, pág. 153).

10 Böll, H.: Werke. Romane und Erzählungen. Billard um halbzehn. Kiepenheuer \& Witsch, Köln. pág. 452. 
De nuevo se enfrentan el presente al pasado. Se describe una imagen del pasado de, por ejemplo, el profesor Brühl. Este profesor, de tendencias nacionalsocialistas, al escuchar cómo fusilan a unos desertores junto al colegio, comenta:

«So wird es allen gehen», sagte Brühl, «die sich weigern, unsere heilige deutsche Erde gegen die jüdischen Yankees zu verteidigen» ${ }^{11}$.

Este mismo profesor es catedrático de pedagogía en una universidad. Quizás sea aun más claro el caso del joven Kalick:

«Er hatte mich vor zwei Jahren einmal eingeladen, um sich mit mir zu versöhnen. Sollte ich ihm etwa verzeihen, da $\beta$ Georg, der Waisenjunge, beim übem mit einer Panzerfaust tödlich verunglückt war oder da $\beta$ er mich, einen Zehnjährigen, wegen Defätismus angezeigt und auf Härte, unnachgiebige Härte bestanden hatte?» ${ }^{12}$.

Y precisamente a este personaje se le da una de las más preciadas condecoraciones al mérito:

«In der Abendzeitung stand, er habe das Bundesverdienstkreuz bekommen wegen «seiner Verdienste um die Verbreitung des demokratischen Gedankens in der Jugend» ${ }^{13}$.

Llaman la atención dos anacronías que, excepcionalmente en la obra de Böll, no se retrotraen al pasado, sino que se proyectan en el futuro. Es el caso del capítulo 14 íntegro y de parte de los capítulos 19 y 23 . Estas prolepsis, que quizás debieran considerarse como una sola, ya que retoman el tema que se introduce en el capítulo 14, describen a Marie como ama de casa y madre de una niña. Hay que tener en cuenta que, en el relato primero, la antigua compañera de Schnier está recién casada con un amigo de la juventud y que este acude a la estación para verla a su regreso de la luna de miel.

La estructura de Ansichten eines Clowns se caracteriza por sus numerosas y constantes anacronías. Es una estructura elaborada, en la que estas son imprescindibles para ir más allá de las tres horas y media que Böll se da como plazo para escribir sobre la historia más reciente de la R.F.A. y su presente.

En la novela que se publica en 1971, Gruppenbild mit Dame no se puede hablar de una estructura narrativa en si. No existe como tal. No se trata de una novela, sino de un informe. Lo que sustenta la acción, que se desarrolla ante los ojos del lector, son las informaciones que un narrador (autotitulado irónicamente «der Verf.») va almacenando sobre el personaje central del libro. El narrador no sabe más de lo que va escribiendo en sus notas. Este narrador nos ofrece, desde su punto de vista (condicionado, desde luego, por los testigos que se procura), las dos historias que se desarrollan: la vida de Leni, objeto de sus investigaciones y la misma investigación en sí. No se sabe con qué finalidad lo hace, aunque indica que lo hace en cumplimiento de un trabajo que el lector no sabe exactamente en qué consiste.

11 Böll, H.: Werke. Romane und Erzählungen. Ansichten eines Clowns. kiepenheuer \& Witsch, Köln. pág. 79.

12 y 13 Ibíd. pág. 213. 
La información está más o menos ordenada según contenido, respetando la cronología natural de los sucesos: empieza describiendo la niñez de Leni, su formación, los años de nacismo, guerra y posguerra. Describe, ya casi al final del informe, una breve reunión en casa de Leni. El propio narrador toma parte en esta, de modo que la ficción se torna más real. Es el único momento en que Leni parece una personal real, ya que hasta entonces solo se le han dado al lector referencias que provienen de los testigos que se ha procurado el redactor del informe. Para recalcar el carácter del libro y hacer más verosímil el informe, se añaden al final del mismo la transcripción de varios documentos ${ }^{14}$.

Böll renuncia a una estructura clara en el libro. Lo que sustenta la acción son los múltiples personajes (rozan la treintena) con los que se entrevista el redactor. Y es la historia de Leni, vista de tantas perspectivas distintas, la que le da pie a Böll para llevar a cabo un retrato global de la sociedad que ya el título sugiere.

Después de esta novela de estructura tan atípica, publica en 1979 Fürsorgliche Belagerung. Esta novela sigue el mismo esquema que Ansichten eines Clowns: hay un relato primero que se reduce a dos días y una mañana ${ }^{15}$. Si en la obra de 1963 se narra todo desde el punto de vista de su narrador y protagonista, en Fürsorgliche Belagerung se van alternando las perspectivas de los ocho personajes principales. Los monólogos interiores de los personajes nos dejan ver, de nuevo, el presente de la R.F.A. en los años setenta.

Fürsorgliche Belagerung analiza la sociedad alemana de estos años, reflejando el miedo del Estado ante el comunismo; la obsesión del mismo por la seguridad, obsesión que le lleva a sacrificar las energías de una juventud a la que considera peligrosa y no le permite ejercer el oficio para el que se ha preparado esta; el gran peso de la industria (de la que no se deja de recordar, tal como se hace en Gruppenbild mit Dame su relación con el nazismo), que no duda en destrozar un pueblo entero para ganar energía sin tener en cuenta los daños humanos y ecológicos que de esta decisión surgen.

Böll escoge la familia de un gran magnate de la industria (y dueño incluso de una revista que no ofrece información, sino contenidos ideológicos — ¿habría que ver aquí una nueva alusión al 'Bild-Zeitung' de Die verlorene Ehre...?-) que vive ahogada en medidas de seguridad y sin embargo está convencida de que éstas son inútiles: si el atentado que se ha planeado fracasa, no es por la eficacia de las medidas de seguridad, sino por la decisión de la propia terrorista, Verónica, nuera del magnate contra quien iba dirigido el atentado.

14 Esta misma técnica la utilizará en la narración Die verlorene Ehre der Katharina Blum, en la que resulta interesante constatar algunas similitudes con Gruppenbild... En cierta manera se puede considerar esta narración como la prolongación de una idea que aparece sugerida en la novela. No se trata solo del carácter de las protagonistas, sino del papel de la prensa, que aparece en ambas obras como un instrumento generador de violencia y manipulador de la conciencia del ciudadano medio.

15 Resulta un poco forzada esta reducción temporal, ya que la acción no resulta verosímil en cierto momento: desde el final de la segunda tarde (en que una conversación privada llega a oidos de los agentes de seguridad a pesar de las precauciones que los interlocutores toman para que esto no suceda) hasta la mañana en que tiene lugar el entierro que cierra la novela, se supone que los agentes localizan a un terrorista en Estambul, le tienden una emboscada y este muere en un tiroteo. Parece que se ha intentado respetar el marco de los tres días que se ha impuesto el narrador a toda costa. 
Si bien no es original en su estructura, lo es en su tema; por el ámbito en que se desenvuelve: no todos los «heroes» son, como casi siempre en Böll, seres casi al márgen de la sociedad, ya sea voluntaria o involuntariamente.

En Fürsorgliche Belagerung se centra la acción en varios núcleos: el matrimonio de los Tolm (el gran magnate), perfectamente integrado en la sociedad y los tres hijos del mismo: Rolf, Sabine y Herbert. Los tres, de una manera o de otra fuera de la sociedad: Rolf no puede ejercer su trabajo (Berufsverbot) a causa de su pasado estudiantil; Sabine se coloca al margen de la sociedad al abandonar a su marido, un hombre de gran éxito en los negocios y en la política. Herbert es un filosofo de izquierdas, que conscientemente se aparta de la sociedad alemana, cuyo sistema desprecia. Los tres jóvenes son, en mayor o menor medida, resultado del movimiento estudiantil de los años 60 .

Böll transforma en novela lo que en más de una ocasión se ha preguntado: si vale la pena sacrificar la libertad del individuo y de las sociedades por una seguridad más bien ficticia:

«Langsam, unmerklich, Stück für Stück kann die Freiheit der Sicherheit geopfert werden, wenn die Angst nur immer wieder geschürt wird, auch genährt» ${ }^{16}$.

En Frauen vor Flußlandschaft, publicada en 1985, nos sorprende Böll con una técnica que no ha utilizado antes en sus novelas. Esta se compone exclusivamente de diálogos y monólogos interiores ${ }^{17}$; cada capítulo tiene un interlocutor central. Las protagonistas son, en realidad, la sociedad alemana de los ochenta y la clase que la manipula.

De nuevo se describe el presente a través del prisma del pasado. Y el retrato que resulta es el que Böll nos ofrece: un antiguo nazi ministro de la R.F.A.

«Erika: (...) Ja, und dann tauchte Blaukrämer auf, der war ein Nazi gewesen, und Halberkramm, der war kein Nazi gewesen das hat Chundt geschickt gemacht. Und das Bingerle, wie ihr ihn jetzt nennt, der war weder das eine noch das andere, nur ein gieriger Hund. Und jetzt Hermann, ist's genug. Hab' ich recht gehört heut' nacht? Blaukrämer soll Minister werden? Blaukrämer?» ${ }^{18}$.

La finalidad:

«Erika: (...) die Grenzer der Zumutbarkeit erweitern» ${ }^{19}$.

El relato primero abarca tres días, en los que se «destrona» un ministro y se crea uno nuevo, aunque son las anacronías las que le llevan, de nuevo, a fundamentar la crítica del presente en el pasado. No se puede decir que esta obra sea, desde el punto de vista de la técnica narrativa una estación más o la culminación de una evolución, sino un experimento, al trasladar estructuras del radiodrama a las de la novela. Böll no aclara los mecanismos de la política. Solo plasma

16 Böll, H.: Vermintes Gelände. Essayistische Schriften 1977-1981. 1982, pág. 123.

17 Se asemeja más, en cuanto a estructura, a un radiodrama.

18 Böll, H.: Frauen vor Flußlandschaft. Kiepenheuer \& Witsch, Köln, 1985, pág. 33.

19 Ibíd, pág. 34. 
un algo difuso, oscuro, sobre el que se proyecta la sombra de la era de Adenauer o de Kiesinger. Los personajes no han sido sacados del mundo político de Bonn, sino del propio mundo literario de Böll.

Es característico de Heinrich Böll ese definir y criticar la sociedad alemana del momento a través de imágenes rescatadas del pasado y confrontadas con el presente. El resultado es perverso, porque la sociedad lo es; es un retrato que no propone tampoco ninguna alternativa, ya que no es esa la misión del escritor.

El resultado es una sátira: Heinrich Böll es un escritor especialmente crítico, y nada escapa a su pluma. Ni Iglesia ni Estado, ni ejército. Sin embargo, aunque Böll condena estas instituciones, siempre deja un resquicio a la esperanza que se asienta en el individuo.

Böll se apoya más en la biografía de sus personajes que en la obra en sí. Esto resulta patente sobre todo en las obras en que la estructura de las mismas ha quedado en segundo lugar, al pasar aquella al primer plano, como es el caso de Gruppenbild... Si se aprecia una evolución y una mayor complejidad en la arquitectura de sus novelas: Wo warst du, Adam? se asemeja a una serie de narraciones breves enlazadas entre si por medio de un personaje; en Und sagte kein einziges Wort la técnica es semejante. En ambas el eje temporal se desarrolla linealmente, sin apenas rupturas. Haus ohne Hüter es más compleja que las anteriores por los personajes y situaciones en que estos de desenvuelven aunque su estructura es semejante a la de las primeras novelas: en el eje temporal, de desarrollo lineal, se van sucediendo los capítulos protagonizados casi exclusivamente por uno o más personajes. Pero las novelas que siguen están algo más elaboradas: Billard um halbzehn, Ansichten eines Clowns y Fürsorgliche Belagerung muestran técnicas nuevas aunque no exclusivas de $\mathrm{H}$. Böll: la ruptura de la linelidad del eje temporal mediante anacronías y el uso de la técnica de contrapunto.

Las novelas mas originales en la obra de Böll, son Gruppenbild mit Dame y Frauen vor Flußlandschaft, que en realidad carecen de estructura en sí.

El mérito de Heinrich Böll no reside en su aportación estilística o formal a la narrativa alemana del siglo $\mathrm{XX}$, sino en el mensaje que sus obras sustentan.

Böll contrasta el presente y el pasado de sus personajes en momentos muy concretos. Colecciona imágenes, como el Hans Schnier de Ansichten eines Clowns. Es la memoria de una sociedad que tiende a olvidar demasiado rápido el pasado por considerarlo lejano y considerar, erróneamente, que por estar tan lejos en el tiempo ya no tiene nada que ver con el presente. Cuando en realidad el pasado sigue existiendo en el presente. 